\title{
Address by the President of the Institute and Faculty of Actuaries Mr Colin Wilson
}

[Institute and Faculty of Actuaries, 23 June 2016]

\section{Contact \\ presidents@actuaries.org.uk}

The President (Mr D.C.E. Wilson, F.I.A.): Good evening and welcome to Staple Inn for the 2016 Presidential Address.

\section{Introduction}

Our profession has faced unprecedented change over the past few decades. Some of that change has been for the better - for example seeing us diversify into new fields. Some of that change poses a real threat. What is clear to me is that if we are going to remain relevant and sustainable as a profession, we need to innovate. That is why I have entitled my Presidential Address "Sustainability through innovation".

The long-term sustainability of our profession has been the focus of recent strategic thinking by your Council, some of which I would like to share with you tonight. I would also like to share my own hopes and ambitions for my year as President, and my vision for the actuarial profession I would like to see in the future. In doing so, I will also tell you a bit about myself and what drives me.

I am delighted to be joined by members of my family here, at Staple Inn, tonight, as well as members of Council and the Presidential team.

It is a privilege to serve my profession, and I am truly honoured that my fellow Council members have chosen me as your President. I am following in the footsteps of some great actuaries. Immediate Past President Fiona Morrison fulfilled her role as President with characteristic passion, diligence and good humour - I am grateful to her for all the help and guidance she has given me over the past year. And it has been a pleasure to work with her predecessor Nick Salter during his time on the Presidential team. I have been inspired by his leadership and clear thinking. I would also like to take this opportunity to welcome Marjorie Ngwenya to the team, as President-elect, and to thank Council and the Executive for their support.

Of course, today is a momentous day. Some have called it "a once in a lifetime opportunity" to shape the future. Actually, I am not talking about the Referendum on UK membership of the European Union, I am referring to the election of our new Council members and the part they will play! I would like to congratulate all those who were elected. I am looking forward to working with you over the next few years.

At the heart of the IFoA's strategy is ensuring the sustainability of our profession. And innovation will play a key role. It is easy to think of innovation as only relevant for a part of the 
profession - perhaps the part not currently employed in our longest established areas of pensions and insurance. But that would be a mistake.

There is a clear threat to the work of the profession from increasingly sophisticated IT and from other, less-qualified, risk analysts. And this is combined with the long-term decline in defined benefit pensions and consolidation of the insurance industry. So, innovation is important for our sustainability.

Much has been written about how to innovate and how to create an environment that encourages innovation. I do not intend to dwell on this aspect this evening. But most thinkers are agreed that a key element is Collaboration. Problem-solving is made easier and innovation is enhanced by sharing ideas and working with others.

Innovation can take many forms. It may mean developing better ways of doing things we are already doing; it may mean changing how we apply our insights in our traditional fields; or it may mean applying actuarial skills in completely new areas. It can be evolutionary or revolutionary. But with so much of our work being ultimately based on data in a world where the volume of available data continues to increase so rapidly, innovation is a clear priority.

If you do not agree, think about how innovative we have actually been over the last 10 years. The nature of the work carried out by actuaries today is already vastly different from what it was 10 years ago, let alone 20 or more.

And within the working lives of today's young actuaries, we can expect even more change as both retirement ages and the pace of change continue to increase.

So, innovation is not just an aspiration. It is an imperative.

\section{Personal Motivation}

But let me start by telling you a bit about myself and my values.

I spent 10 years working in operational research in the defence industry before deciding to become an actuary. So I have seen the difference that becoming a professional makes, and I am proud of being an actuary. I have volunteered for the profession for many years, both because I believe that we owe it to our profession, and to society, to give something back, and because I have found it rewarding for me personally.

As an actuary, I have worked in a number of different fields, starting in life insurance then investment and risk, but also covering some pensions as well as general insurance and wider fields. I have worked in both the private and public sectors, and in both operational and consulting roles.

So I have had the opportunity to see how valuable the actuarial skillset is, and its applicability in a wide variety of situations. And this is reflected in Council's thinking on our future education strategy - we want to equip all our members with both the core skills and the flexibility that they will need to respond to a changing world. 
But our qualifications are just part of what it means to be an actuary. The professionalism and the reputation of actuaries are also key strengths. They underpin what we do, how we do it, and how we are perceived. It is this professionalism that we seek to protect with our light-touch, principles-based and outcomes-focussed approach to regulation.

I am the UK's Deputy Government Actuary, where the idea of public service underpins everything we do. So the words in the IFoA's Royal Charter about acting in the public interest definitely resonate with me, on both a personal and professional level.

I believe that everyone matters. So, we need to think about the consequences of our actions for other people. To me, this is what it means to act "in the public interest" - we must look and act beyond our own narrow interests. And I personally believe that we need to go beyond the human race and consider the natural environment in its entirety.

It is important that we leave a good inheritance - a sustainable inheritance - for future generations. But what does this mean? The UN Brundtland Report defined sustainable development as: "development that meets the needs of the present, without compromising the ability of future generations to meet their own needs." I believe that we have a moral responsibility to consider these future generations in all that we do. And I am confident that doing so will contribute to the sustainability of our own profession.

So that is what drives me. But what does it mean in relation to my role as President?

\section{My Focus as President}

For me, this is not about creating a personal legacy. I am here because I want to make a difference to our profession and to society. This will need collaboration with others, both within and outside our profession.

Step back for a moment and think about some of the big challenges facing society today:

- The ageing population and intergenerational fairness;

- Climate change, investment in infrastructure and long-term sustainability;

- Poverty, inequality and the future of healthcare; and

- Privacy and big data.

Long-term thinking is vital to all these issues. To take climate change as an example, the IFoA recognises the serious risk that climate change poses to society and believes that actuaries are well placed to work with governments, business and other stakeholders to help better understand the long-term consequences of climate change, and to help develop policy options to respond to these risks.

So if you care about any of these issues, I urge you to think about how you could make a contribution as an actuary. I believe that if you can help, you should help. To quote Ronnie Bowie, the first President of the IFoA: "the world needs actuaries".

The IFoA is a fundamentally different organisation from both the Institute and the Faculty of 20 years ago. And this means that the role of President has changed. We have a core strategy, set by Council. We have corporate plans that set out what we will do to achieve our aims. And we have 
both a highly professional Executive, ably led by Derek Cribb, and a large body of volunteers that work hard together to ensure we achieve our ambitions. So, I have no desire to come in as President and change the direction of a high performing organisation.

I have said that it is the IFoA's Council that sets the direction for our profession. We need to be confident that this body operates as effectively as possible. This is not to say that our Council is not working well already. But it is not fully representative of the diversity of our profession and succession planning is a recurring issue. I am sure there is a lot we can learn by exploring what other professional bodies do in this area. I shall therefore be sponsoring a review of the composition of Council.

But this review is just one part of what I want to focus on in my year as President. My primary focus is much more outward-facing.

David Hare, in his Presidential Address, spoke about the importance of actuaries ramping up their relevance - to employers, opinion-makers and the world at large. Nick Salter spoke about the importance of embracing diversity in all its forms, and the benefits to be gained from diverse perspectives. And Fiona Morrison spoke about the need to promote the value of the actuarial skillset more widely. All of these themes are, at their core, designed to ensure a stronger, more sustainable profession. So I want to continue their good work by focussing on an aspect of the profession's work which I believe is complementary, and critical to the future sustainability of our profession: thought leadership. I will say more about this in a minute.

\section{Strategy and Thought Leadership}

But first, let me share more of Council's thinking on our strategic direction. Over the past year, Council has spent a lot of time reviewing our strategy to make sure it remains fit for purpose.

Our mission has not changed: we still seek "in the public interest, to advance all matters relevant to actuarial science and its application and to regulate and promote the actuarial profession". And our vision is still that, "we will serve the public interest by ensuring that, where there is uncertainty of future financial outcomes, actuaries are trusted and sought after for their valued analysis and authority."

But we cannot ignore the changes in the external environment in which actuaries work. The world has moved on dramatically since our last strategy was written, 5 years ago. So we have refreshed this strategy to reflect these changes and ensure that we remain relevant.

The revised strategy sets out more radical ambitions for what we want to achieve as a professional body. Rather than being seen as a leading actuarial body, we want to be seen as an exemplar professional body, full stop. As I have already mentioned, we are adapting our qualification offering to meet the current and future needs of the evolving market. We are continuing to focus on delivering proportionate regulation of our members. We are increasing our technological capability and international representation, to ensure the best support is provided to our members all around the world.

And we are developing a higher public profile to promote actuarial science more widely. This, to me, is critical to our profession - indeed, it is enshrined as part of our Charter objectives, which is why Fiona focussed on "promote" in her Presidential year. This means that we will be more outspoken on matters where the actuarial voice can add value. 
When speaking up, we do so from the solid platform of our expertise and a strong evidence base. And at the core of this evidence base is our research. So I am really pleased at the significant boost the profession recently announced to our sponsored research, through the expanded Actuarial Research Centre.

But we also need to make sure that we make best use of this research. And this brings me back to thought leadership. For a profession such as ours, thought leadership is a vital form of innovation.

So what do I mean when I say thought leadership?

Let me give you a couple of definitions among many:

- One view is that thought leadership is "Using expertise and insight to create or extend thinking and understanding in a way that others can benefit from."

- According to another view, thought leadership is "Adding genuine value by sharing knowledge and information that matters"

These two definitions reflect different aspects. Sometimes we need to use our specialist expertise to create new thinking. Sometimes we just need to recognise what is important and pass it on.

So thought leadership is not just about deep, technical research. It is not just about being a "learned society". These activities are valuable, but inwardly focussed. For me, thought leadership is about being outwardly focussed and taking our thinking out into the wider world. It is about recognising the value that other professionals bring, and collaborating with others to look at solving problems in new ways. And it is about sharing the results, both with our own members and more widely.

And it is this collaboration which is at the centre of my vision for the IFoA's thought leadership. Collaboration is necessary across the profession as well as beyond it: we need to look across the practice areas, and across geographical boundaries, to take a non-siloed approach to research. We can learn a lot by collaborating with those from different backgrounds. And often such collaboration is vital to solve the most complex problems.

So whether we are developing our own thought-provoking research which has wide applicability or bringing together existing thinking to shed new light on the work of others, we will achieve more when we work in partnership with others. As President, I will be working closely with the IFoA's Research and Thought Leadership Committee to help make this happen.

So, what impact do I hope that prioritising thought leadership will have on the profession? It boils down to three ambitions:

- I want us to be seen as a dynamic, forward thinking professional body - one that remains relevant, outwardly focussed and swiftly responds to changes in the external environment.

- I want other bodies, policy makers and business leaders to listen to us and hear what we say, and to talk about ideas that have been generated by the profession.

- And I want these other bodies to come to us with questions because they recognise the value of the actuarial voice. 


\section{Wider Fields}

There are many activities beyond our established areas of work in which actuarial thinking can add real value - the so called "wider fields". We have the skills to help, the knowledge to share and the expertise to innovate. And I believe it is in the public interest for us to do so.

Now, I know that we have been talking about the importance of actuaries getting into wider fields for many years. And I know that some amongst you will say: "Why bother? Nothing has changed!" Well, I disagree. We are seeing actuaries around the world moving into new areas.

Sometimes this happens out of necessity. Australia is a good example. Here, the demand for actuaries in established industries declined rapidly, due to fundamental changes in the life insurance and pensions landscape. This brought the sustainability of the Australian actuarial profession into sharp focus. Actuaries had to promote the value of their skillset to a new business audience, they had to innovate, in order to survive. And this is exactly what they did. A growing number of actuaries in Australia are now working in less traditional areas, such as fund management, banking and data analytics. And they are succeeding.

Now I am not saying that IFoA members are facing the same drop in demand everywhere. But clearly the world is changing, and we, as actuaries, need to evolve to survive.

But this is not just about moving into new fields. It is about using our skills and experiences in new ways, in existing contexts. I have seen this first hand, in my day job working for the UK Government. A few years ago, the Government Actuary's Department was asked to join a multi-disciplinary team reviewing quality assurance for the most important models within government. Some big decisions depend on the results of these models. Working with other professionals was enlightening and led to some valuable insights on model risk that are making a real difference. Since then the Government has recognised the value that actuaries' financial modelling skills can add in areas such as

- predicting demand for transport;

- estimating future pupil numbers for schools; and

- projecting cash flows from repayment of student loans.

What these examples demonstrate is that if actuaries want to move into new fields, or use their skills in new ways, they can - and they do. And we, as the professional body, need to support them, and smooth that transition. But how can we best do this?

I believe that the most important thing you can do when bringing up children is to give them both roots and wings. In the context of the IFoA, it is essential that we ground our actuaries in a core skillset to give them roots. But we also need to encourage flexibility and adaptability to enable them to grow the wings that will help them to fly in their chosen careers.

The Australian experience will not be an isolated incident, and is likely to become a global trend. We, as your professional body, can support you as the world changes. But you, our members, are the real innovators. And as innovators, you hold the key to unlocking these opportunities. It is your thought leadership will ensure actuaries' relevance in established fields, and open doors to wider fields. 


\section{Examples of Innovation}

The World Bank is another great example of where the actuarial skillset is being utilised in an innovative way and is serving the public interest, in this case in the fight against poverty.

Think about what happens when there is a natural catastrophe, whether it is drought, a flood, an earthquake. Large numbers of households, farmers and businesses are likely to be affected. These people will need money to recover and to re-establish their businesses. Often it is a real problem getting this money to the people in need, and delays can have serious consequences for health and livelihoods.

What the World Bank have done, with the help of their in-house actuaries and assisted by the UK Government Actuary's Department, is to enable governments to quantify the financial impact of risks, such as natural disasters, and to develop financial strategies to manage them when they occur, thus enhancing financial resilience. And as countries become more sophisticated, there is increasing demand for information and tools to make evidence-based decisions. Developing these tools needs expertise in economics, in finance and in statistics: in other words it needs actuaries!

This is an example of where the work that actuaries do can really make a difference to the lives of many individuals, because getting it right really matters for the people affected. And I am sure there are many other examples where the work of actuaries is leading to better outcomes.

In fact my guess is that this already applies to many of us. Think about what you currently do. When people ask you what you do, what do you say? Perhaps it is something like "I work in insurance" or "I manage a pension fund".

What if, instead, your answer showed the effect of your work? Think about it. Do you simply manage a pension fund? Or do you help make sure that people have enough savings to live off in their old age? Do you work in insurance? Or do you help make sure that, if something bad happens, people have financial security during their worst moments?

So we need to speak out. I recently heard of a US business leader who said that his actuarial colleagues were the most "thoughtful, intellectually grounded and strategic thinkers" he had come across, but this does not get unleashed unless someone else asks them the right questions. Let us turn that round and start providing the insights that really make a difference without waiting to be asked.

I am sure you can think of your own examples of issues affecting society where actuaries could have added value, had they been involved. The onus is on us, as actuaries, to think creatively, to think innovatively, about how we can make an impact.

As we wait for the result of today's referendum we might reflect on the UK General Election in 2015, and ask just how did the opinion polls get it so wrong? Could the outcome have been predicted? With so much data available to polling companies, in theory this should not have been so challenging. So would having an actuary involved in modelling the outcomes have generated a different result? We are taught when making predictions to take into account biases, selection and sampling effects, and so on. And might a different prediction actually have made a difference to the outcome of the election? Well, it might have affected political campaigning, how the election was being reported in the media and voter turnout. And all of these could have had an impact. Certainly, I would argue that, in a democracy, people are entitled to the best information that can be obtained and that actuaries might have been able to help deliver this. 


\section{Looking to the Future}

Looking to the future, my hope is that, by shining a spotlight on thought leadership, and championing the benefits of innovation in my Presidential year, I will be able to make a positive impact. By building on the foundations of those that came before me, I hope to feed the roots of our profession, helping to sustain it for the future, and enabling IFoA members to spread their wings.

So how will I know at the end of my term as President if I have been successful? Well, for me, success is about what the profession looks like in 5, 10 or 20 years' time, not at the end of my presidential year.

The answer comes back to our strategy. I want to ensure we continue on a path that will achieve our vision and ensure the future of our profession. I want to help us to be more outward-facing and to collaborate more widely with those outside our profession. And I want to turn what we are doing on thought leadership into business as usual.

So my vision is based on the three ambitions I described earlier. Let us be

- a dynamic, forward thinking professional body;

- a profession that generates ideas that others listen to and talk about; and

- a "go to" body for other decision makers and influencers.

This will demonstrate to me that we are getting it right.

I said earlier that I believe we all have an obligation to contribute and to help society where we can. And this requires creative thinking and innovation. So what can you do, as a member of the IFoA, to make a difference?

I have already talked about the value of highlighting the effect of our work and not just what we do. Acting as ambassadors for our profession is something we can all do, whether we work in pensions, in insurance or in wider fields. We can all contribute to a wider understanding of what actuaries do, and help sell our skills to those who need them. We can all take the time to think about what we can do to help people. To listen to them, to empathise with them, and to engage with them, and with the challenges faced by businesses and in industries that we may never have worked in before.

So please keep this in mind when you go about your daily work. I have set out my vision for a sustainable profession, but this is not about me as President. We know we can do more as a profession and as individuals. You all have a role in helping to address society's problems. To make a real difference we need as many of you as possible to be innovators, to be thought leaders and to be ambassadors.

So I urge you to do three things:

- to think broadly in all you do;

- to talk positively about your work, and the work of actuaries; and

- to engage collaboratively with others.

In the words of Thomas Edison: "if we do what we are capable of, we will astound ourselves."

Do this, and we will ensure the sustainability of our valued profession.

Thank you. 